\title{
Attention or Appreciation? The Impact of Feedback on Online Volunteering
}

\author{
Xue (Jane) Tan \\ Indiana University \\ janetan@iu.edu
}

\author{
Fujie Jin \\ Indiana University \\ jinf@indiana.edu
}

\author{
Alan Dennis \\ Indiana University \\ ardennis@indiana.edu
}

\begin{abstract}
We examine how different types of feedback influence online volunteer contributions in the context of online consultations for college entrance applications, which requires the volunteer counselor and the person receiving help (the counselee) to be online at the same time. We investigate the impact of two types of feedback on volunteers' participation: 1) appreciation, as reflected in the number of positive ratings received by a counselor from counselees; and 2) attention, as reflected in the readership of a counselor's profile page. We find that appreciation encourages the volunteer to engage in more helping behavior, likely because it can activate the volunteer's altruistic motivation. In contrast, attention discourages volunteers to offer more help, possibly because they feel they have accomplished enough or because they feel passed over when they receive a lot of attention but few requests for consultations. The findings suggest that platform designers should encourage appreciation from those helped and provide more nuanced feedback about attention.
\end{abstract}

\section{Introduction}

The Internet has changed the landscape of volunteerism by enabling volunteers to help others located thousands of miles apart. The design of systems to encourage and sustain users' voluntary contribution in online platforms have received much research attention [26]. Past works have focused mostly on simple voluntary tasks such as answering a question, writing a review, editing a Wikipedia entry, or categorizing images $[1,7,11,22]$. These tasks are termed micro-volunteering because the basic unit of work is small and can be completed with little effort and few time constraints [21,29].

However, other types of tasks such as IT support, researching, teaching, and consulting, cannot be easily divided into small units and are often time-sensitive, requiring a higher level of work in a given time frame.
For example, LinkedIn has started an online mentoring service that connects users with volunteer mentors for career advice through instant messenger. Volunteers are expected to respond in a timely fashion [25]. The time restriction is also reflected in the episodic nature of some tasks. For example, online consultation for college admissions is relevant at a certain time of the year rather than on a routine basis. These timesensitive tasks usually entail high skill levels and are critical for non-profit organizations that face wide ranges of budgetary constraints, human needs, and a shrinking base of available resources [8].

Understanding the factors that motivate volunteers to undertake time-sensitive tasks is a key issue that has substantial theoretical and practical value. AmichaiHamburger [2] proposed a framework for the general concept of online volunteerism (not limited to microvolunteering), but empirical evidence is sparse. Some studies use surveys to identify main motives for online voluntary behavior [17], but these studies fall short of establishing the link between intention and behavior, which is critical for prosocial activities [14].

Sustaining volunteer participation is critical to the survival of online volunteering platforms because the low participation of volunteers likely leads to user dissatisfaction and potential withdraw behavior. Timesensitive tasks have difficulty in volunteer recruitment and retention because they require more effort [2]. Information technology has the potential to overcome such limitations by scaling up global efforts to mobilize volunteers, facilitating interaction and serving marginalized communities, as noted in a volunteerism report from the United Nations [36]. To exploit the potential of technology, it is essential to understand how online platform features affect volunteers' participation [29].

We investigate an online platform that provides college admission assistance to high school students in China. Volunteers are recruited from colleges and are required to take a training session before providing consultations. They expend effort to create profile pages providing their current school and major as well as application histories for high school students to browse and inform their own decisions. A high school 
student counselee can send a request to a volunteer counselor for an online consultation, and if the request is accepted, the counselee can initiate online dialogue with the counselor for personalized assistance. This is different from volunteers' provision of personal application history that will enrich the application database for the consumption of all high school students.

Previous studies have identified several factors that affect participation in voluntary behaviors, with effortbased feedback receiving much attention [18, 20, 29]. We focus on two technological manifestations of feedback. The first is appreciation, which we measure using the number of five-star ratings a counselor receives from counselees. Less than $1 \%$ of the volunteers in our sample received a rating lower than five-stars, suggesting that students only rated highquality experiences, and avoided leaving low ratings [24]. We draw on the self-verification theory to explain how this technology feature can be used to activate the motive of altruism [26]. The second is attention, which we measure as the number of a volunteer's profile page views. A page view is counted only when a counselee browsed the volunteer's summary profile page and clicked to view his or her full page. This is, therefore, attention to a counselor's effort to self-report his or her college application history $[6,13]$. We draw on the social learning theory to discuss how this social information can affect volunteers' participation [4].

We find that appreciation positively affects volunteers' participation (by increasing the subsequent consultations), but attention works in the opposite direction. While the positive effect of appreciation is intuitive and consistent with past research, the second result seems counterintuitive. Why would volunteers become less likely to participate when they receive more attention? We provide two explanations based on social learning theory which posits that people form perceptions from the observation of others' reactions. Volunteers may perceive many page views as indicating that they already have made enough contributions and thus may be reluctant to invest more effort. Alternatively, volunteers may perceive a high page view count with few consultation requests as a signal that their expertise is not valued because they have been passed over in favor of other volunteers.

We make four contributions to online volunteerism research. First, by showing the different ways appreciation and attention affect volunteer's participation, our findings add to the understanding of these different feedback mechanisms. Second, we investigated two moderators, the length of an answer to an optional question and the peer group size on the platform for each volunteer, that can be used to examine the underlying mechanisms of voluntary participation. Psychologists consider the effect of feedback intervention on performance to be highly contextual, and a better understanding of moderators is greatly needed [23]. Third, we provide two instrumental variables to identify the causal impact of feedback on participation. These help to account for the endogeneity concerns associated with feedback measures [12]. They have the potential to be applied to a wide spectrum of studies. Finally, our results have implications for the design of online volunteering platforms that feature time-sensitive tasks. Platform designers should encourage feedback that reflects the value of users' effort and discourage feedback that may send negative messages.

\section{Research Context}

The college application consultation platform we studied was a corporate social responsibility program initiated by an education company in China. It enables college students from different regions, universities and majors to volunteer to assist high school students with their college applications. The target high school students are those who just completed their national entrance exam and received their test scores and need to submit their applications for colleges based on their scores and preferences. The application decisions are time-sensitive since they need to be submitted within a given time-window in June each year for first-round admissions. If not admitted to colleges of their choice, they will complete another application for secondary schools (lower-tier) in July.

The application is a complex decision for students: they not only need to select schools and majors but also list their preferences strategically, since the admission process is sequential but not simultaneous. Colleges review students listing them as their first preference first and only move on to the student pool listing them as second preferences if there are still vacancies left after admitting the first batch meeting their admissions requirement. Thus students need to know about the pool of candidates in previous years to better understand their likelihood of being selected. It also creates a large market for paid advice and consultation. Automated online recommendation services cost about $\$ 50$ and one-on-one consultations about $\$ 500$ (US dollars). This is unaffordable for underprivileged students (e.g., students with low family income or located in remote areas) and necessitates online voluntary consultations to assist students disadvantaged in acquiring information.

This volunteering platform aims to connect high school graduates with current college students who 
have gone through the application process recently. Volunteers are recruited from 652 colleges and secondary schools. They expend effort to go through an online volunteer training program and enter their information into the volunteer database for students to browse. In the profile pages, the volunteers provide information on their real name, major and university they attend, high school they attended, exam scores and college application history; they provide further information such as recommendations, experiences, and tips that high school students can click on a "learn more" button from their profile pages to further explore (Panel a of Figure 1). A volunteer's readership is calculated using the number of clicks for the "learn more" request and displayed both on the profile page and on the search results (Panel b of Figure 1).

\section{Figure 1: Screenshot of Volunteer Profile}

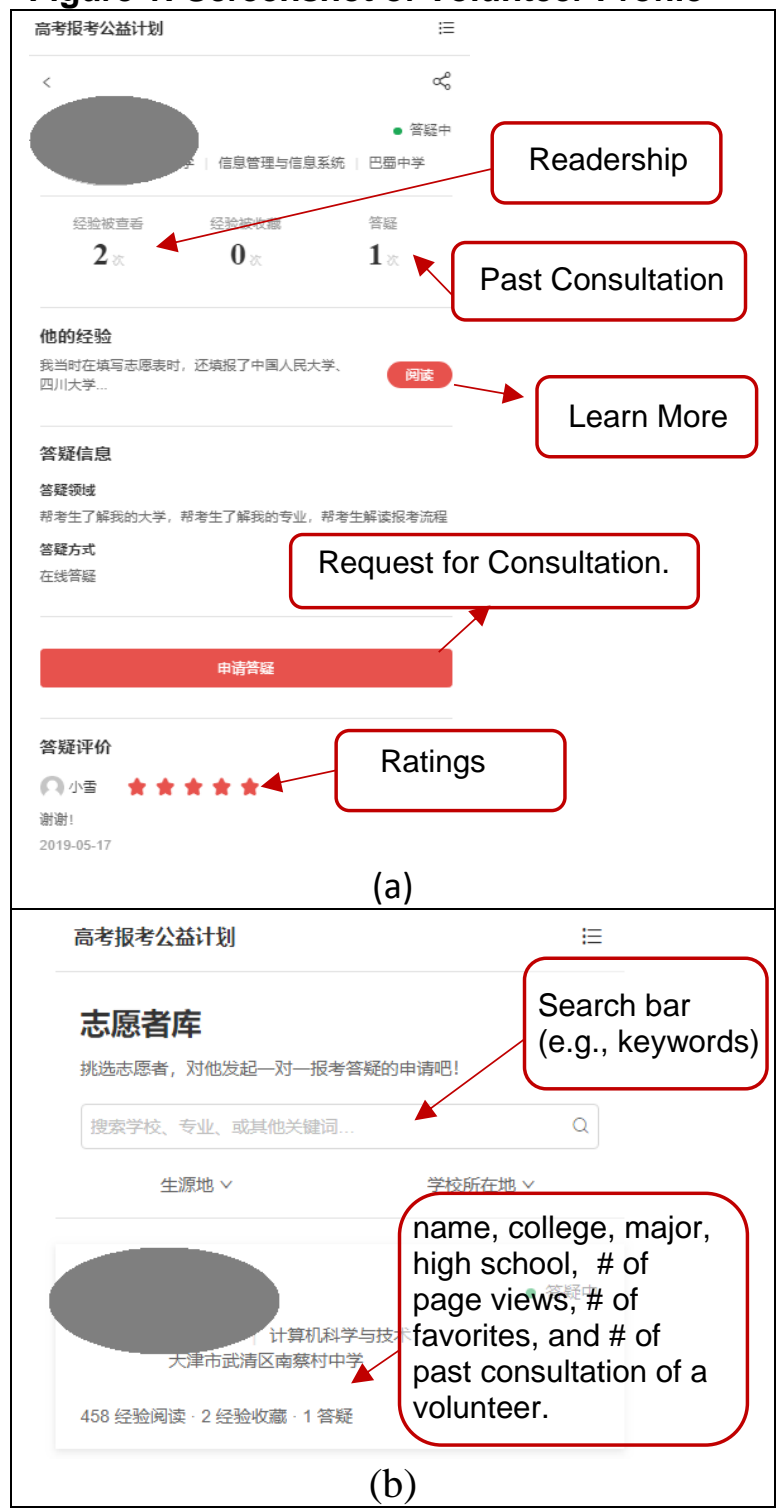

The student can also click the "request for consultation" button to send a request for a private online consultation with the volunteer. They are required to provide their own exam score, preferred colleges, majors and areas to consult on as they submit their request. Volunteers then decide whether to accept the request. A volunteer's past consultation number is listed both on profile pages and in search results. When a consultation is completed, the counselee will be asked to rate the counselor. The rating is voluntary. High school students search for volunteers based on their preferences of city, high school and college (Panel $b$ of Figure 1). The platform design does not have any gamification features.

The initial version listed volunteer with the highest number of completed consultations first. However, this directed many students to a small number of volunteers, who became overloaded with requests. The ranking algorithm was changed to prioritize counselors who have more capacity. This exogenous algorithm change will be used to enhance our identification, as described later in section 4.3.

\section{Theoretical Development}

\subsection{Online Volunteerism}

The theoretical motivation for volunteering has been studied in information systems, social psychology, and organization science [2, 16, 17, 29]. Past research suggests that prosocial volunteering behavior is driven by both intrinsic and extrinsic motivations [15]. Intrinsic motivation includes warm glow, altruism and socializing. Warm glow is the joy of helping others that can originate from a higher level of self-esteem [3]. Altruism is "unselfish concern for the welfare of others" [5, p. 291]. Socializing benefits come from meeting people and being integrated into the community [30]. Extrinsic motivations include better working opportunities through improved communication skills and a better resume. A volunteer's motivation is not static but dynamic and evolves as the volunteer accumulates experience [33].

Harrison [16] noted that many voluntary tasks are episodic. Unlike routine tasks that are performed on a daily basis (e.g., answering a question or proofreading a page of an article), many voluntary activities are performed on isolated occasions. For example, visiting kids in the hospital on Christmas or helping organize the Oscar awards occur only once a year. The voluntary task of college application consultation is also an annual event. Such tasks involve infrequent interaction among volunteers, making it harder to recruit and retain contributors [16]. 


\subsection{Feedback in Voluntary Contribution}

Feedback is the most widely used intervention for reinforcing and shaping people's subsequent behavior [19]. In volunteerism settings, something as simple as a thank-you note can be an effective motivator [37]. Popularity indicators also positively affect both quality and amount of volunteer participation [26, 31].

Our study examines the simultaneous effects of two different feedback cues: the number of page views and user ratings. These two types of cues differ in source, message, and recipient for our context (see Table 1). We consider the impact of each cue in turn.

Table 1: Feedback Comparison

\begin{tabular}{lll}
\hline Rource & $\begin{array}{l}\text { Only a counselee } \\
\text { can rate a counselor }\end{array}$ & $\begin{array}{l}\text { Any user in the } \\
\text { system }\end{array}$ \\
Message & $\begin{array}{l}\text { Appreciation of the } \\
\text { content } \\
\text { Mainly the volunteer }\end{array}$ & $\begin{array}{l}\text { Popularity of } \\
\text { the content } \\
\text { Any user in the } \\
\text { system }\end{array}$ \\
\hline
\end{tabular}

Ratings are a measure of appreciation for the volunteer counselor's work. The appreciation cues are sent by counselees who just completed the online consultation, so they are a genuine reflection of counselees' acknowledgment and gratitude. Such appreciation can activate volunteers' altruistic motivation to improve the welfare of others. It amplifies the feeling of warm glow through an enhancement to volunteers' self-esteem as they obtain confidence from being useful [28]. More importantly, the feedback is a social interaction that creates an attachment between the counselors and counselees [23]. According to the self-verification theory, appreciation will strengthen users' self-perception as an altruistic, useful, and socially conscious person [34]. As a result, the volunteer may become more concerned or empathetic about the high school students who face a critical life decision with limited information. To help these students and further improve self-perception, the volunteer is likely to accept more subsequent consultation requests.

H1: Appreciation positively affects volunteers' decision to accept subsequent consultation requests.

Pageviews are a measure of the attention to and popularity of the volunteer's content. Recall that a page view is only counted if a user clicks to browse the full page, and a page view can be requested by any information seeker in the system. As such, a high page

\footnotetext{
${ }^{1}$ This does not include high school students that are not registered in the system but also accessed the volunteer database. A Chinese
}

view is a collective confirmation that the profile page is worth reading. Attribution theory posits that people use social information cues to infer others' personalities and identity [32]. In online platforms, a personal web page is a typical way to communicate one's identity [27]. Since volunteers reveal their real identity, a high page view indicates a larger audience being aware of their prosocial behavior of registering to be a volunteer and providing personal information for better decision making of others. The larger audience of their prosocial behavior may translate into future social rewards as the high school students may end up going to the same college as the volunteer. It may lead to gratification from the satisfaction of warm glow, just as appreciation. It also reminds and enhances volunteers' helpful identity and drives more helping behavior so that their behavior mirrors their identity. As a result, a volunteer will participate more actively when receiving high attention.

H2: Attention positively affects volunteers' decision to accept subsequent consultation requests.

\section{Method}

\subsection{Data}

Our data is obtained from the June 2018 launch of the college application consultation event. This event attracted 16,908 volunteer counselors and 24,930 high school students ${ }^{1}$. Most high school students browsed through volunteers' profile pages to learn about their application histories without requesting one-on-one consultations, most likely because they already found answers to their questions in the information provided. This also demonstrates the importance of the attention measure as feedback of popularity. We focus on the 1,246 volunteers who received more than one consultation request. Of these volunteers, $201(16 \%)$ received a five-star rating; only $13(<1 \%)$ received a rating that was not five-stars. Thus the ratings in this context differ from product ratings. Users give a fivestar rating to show their appreciation or leave no rating [24]. Therefore, we only focused on volunteers who received five-star ratings or no ratings and consider the former as the appreciation mechanism. We removed the 13 volunteers with lower ratings as outliers. We removed eight volunteers who worked for the platform company and one who had an invalid entrance exam score. We summarize the variables in Table 2 and report the descriptive statistics in Table 3.

article reporting this event can be found here: (accessed on 6/1/2019) https://edu.qq.com/a/20180601/038725.htm 


\subsection{Model}

Our dependent variable is Accept $t_{i t}$ a binary indicator variable for whether the consultation request was accepted. The index of $i$ represents the volunteer and the index of $t$ represents the sequence of consultation requests. For example, if volunteer $i$ received two consultation requests and he/she only accepted the first request, we have Accept $_{i l}=1$ and Accept $_{i 2}=0$. As such, we have a panel dataset where we observe every decision made by the volunteers. We choose to focus on volunteers' decisions to accept consultation requests since it measures volunteers' engagement on platform and also influences high school students' satisfaction with the platform for getting matched to volunteers in a timely manner. Therefore, volunteers' acceptance of consultation requests is essential for the platform to maintain an active contributing user base.

Our main independent variables are NumRating Nit $_{\text {, }}$ the number of five-star feedback ratings by the time she receives the request of sequence $t$, and NumRead ${ }_{i t}$, the number of page views for volunteer $i$ by the time of request of sequence $t$. While some high school students also provided written reviews along with the ratings, such text data is sparse and we decided to leave it out of the analysis.

Table 2: Variable Description

\begin{tabular}{|c|c|}
\hline Variables & Descriptions \\
\hline \multicolumn{2}{|c|}{ Dependent Variable } \\
\hline Acceptit & $\begin{array}{l}\text { A binary variable that takes the } \\
\text { value of } 1 \text { if volunteer } i \text { accepts } \\
\text { the consultation request at time } t \text {. }\end{array}$ \\
\hline \multicolumn{2}{|c|}{ Independent Variables } \\
\hline NumRating $_{i t}$ & $\begin{array}{l}\text { The number of } 5 \text {-star ratings } \\
\text { volunteer } i \text { obtained by } t \text {. }\end{array}$ \\
\hline NumReadit & $\begin{array}{l}\text { The log of the number of views for } \\
\text { the volunteer's experience page. }\end{array}$ \\
\hline \multicolumn{2}{|c|}{ Control Variables } \\
\hline ScoreDiff & $\begin{array}{l}\text { The normalized score difference } \\
\text { between volunteer and student. }\end{array}$ \\
\hline FirstChat $_{i}$ & $\begin{array}{l}\text { Indicator variable that will take the } \\
\text { value of } 1 \text { if it is the first request } \\
\text { received by individual } i \text {. }\end{array}$ \\
\hline ChatCntit & $\begin{array}{l}\text { The number of live chat } \\
\text { consultations conducted by } i \text { at } t \text {. }\end{array}$ \\
\hline TargetSchoolit & $\begin{array}{l}\text { Indicator variable that will take the } \\
\text { value of } 1 \text { if the requestor is } \\
\text { interested in a school that } i \\
\text { studies in or has applied to. }\end{array}$ \\
\hline TargetMajor $_{i t}$ & $\begin{array}{l}\text { Indicator variable that takes the } \\
\text { value of } 1 \text { if the requestor is } \\
\text { interested in a major that } i \text { studies } \\
\text { or has applied to. }\end{array}$ \\
\hline Hour $_{i t}$ & $\begin{array}{l}\text { The hour when the request was } \\
\text { initiated at time t from volunteer } i \text {. }\end{array}$ \\
\hline
\end{tabular}

Recencyit

The number of seconds between the last consultation request and the current one for $i$ at time $t$.

Note: Instruments and moderators are not included in this table but are introduced in corresponding sections.

Table 3: Descriptive Statistics ( $\mathrm{N}=6414)$

\begin{tabular}{|c|c|c|c|c|}
\hline & Mean & S.D. & Min & Max \\
\hline Accept $_{i t}$ & 0.850 & 0.357 & 0 & 1 \\
\hline NumRead $_{\text {it }}$ & 2.031 & 1.258 & 0 & 4.977 \\
\hline NumRating $_{\text {it }}$ & 1.158 & 2.578 & 0 & 22 \\
\hline ScoreDiffit & 0.476 & 0.079 & 0.042 & 1 \\
\hline FirstChat $_{i}$ & 0.2 & 0.4 & 0 & 1 \\
\hline ChatCnt & 6.649 & 10.791 & 0 & 84 \\
\hline T.Schoolit & 0.459 & 0.498 & 0 & 1 \\
\hline T.Major ${ }_{i t}$ & 0.176 & 0.381 & 0 & 1 \\
\hline LenBioi & 3.22 & 1.767 & 0 & 5.545 \\
\hline IVRead $_{\text {it }}$ & 1.808 & 4.821 & 0 & 52 \\
\hline IVRating $_{\text {it }}$ & 2.293 & 1.532 & 0 & 4.511 \\
\hline LenBioi & 3.220 & 1.767 & 0 & 5.545 \\
\hline Group $_{i}$ & 6.090 & 4.569 & 1 & 19 \\
\hline
\end{tabular}

We control for the recency of requests $\left(\right.$ Recency $\left._{i t}\right)$, the number of days elapsed since the start of the consultation event, the test score difference between volunteers and students (ScoreDiff ${ }_{i t}$ ), whether this is the first request received by a volunteer (FirstChat ${ }_{i}$, the number of past consultations $\left(\right.$ ChatCnt $\left._{i t}\right)$, the hour of the day the request was submitted $\left(\right.$ Hour $\left._{i t}\right)$ and whether the major and school match between students and volunteers (TargetSchool ${ }_{i t}$ and TargetMajor ${ }_{i t}$ ). To accommodate the binary outcome with panel data structure and endogenous regressors, we follow previous research and use the linear probability model (LPM) as our modeling framework:

$$
\begin{aligned}
\text { Accept }_{i t}= & \beta_{1} \text { NumRating }_{i t}+\beta_{2} \text { NumRead }_{i t}+ \\
& \boldsymbol{X}_{i t} \boldsymbol{\theta}+\gamma_{i}+\delta_{t}+\varepsilon_{i t},
\end{aligned}
$$

where $\boldsymbol{X}_{i t} \boldsymbol{\theta}=\theta_{1}$ Recency $_{i t}+\theta_{2}$ ScoreDiff $_{i t}+$ $\theta_{3}$ FirstChat $_{i}+\theta_{4}$ ChatCnt $_{i t}+\theta_{5}$ TargetSch $_{i t}+$ $\theta_{6}$ TargetMajor $_{i t}$.

We include the fixed effect terms, $\gamma_{i}$, to control for unobservable volunteer-specific attributes. This controls for all the time-invariant volunteer attributes that likely influence whether she accepts a request, including for example, willingness to help others, ability and experience with volunteer activities. We also include weekly dummies, $\delta_{t}$, to control for common time trends. The model is estimated with an IV-GMM estimator via the Stata Package "xtivreg2."

One major challenge of identifying the parameter of $\beta_{1}$ and $\beta_{2}$ is endogeneity concerns. It has been widely acknowledged that people's motivation for volunteering evolves over time [33]. The initial 
motivation for volunteering is usually based on selfinterest. For example, gaining experience to improve one's resume for a better future career is one important motivation for millennial volunteers [10]. As volunteers accumulate experience, they may shift their motivation to altruism [8]. Such time-varying unobservable is likely to be correlated with the independent variables-volunteers who receive positive ratings may be those whose motivation easily transitions to altruism and it is hard to tease out the factors driving their continued participation. Similarly, those who are unlikely to shift to altruistic motivation will withdraw after the initial effort regardless of the attention they received, making the attention effect spurious. We address this issue in the next section.

\subsection{Identification}

We account for the abovementioned endogeneity issue with instrumental variables that are correlated with the endogenous variables but not the outcome variables. Intuitively, the link from the independent variables to the outcome is not causal if the outcome does not change with the instruments whose influence on the outcome can only be manifested through the endogenous variables. First, we use the exogenous shock in the platform's ranking algorithm to construct an instrument for the attention measure. On June $24^{\text {th }}$, 2018, the platform implemented a change in the sorting order of volunteer counselors in search results. Prior to the change, the search results appeared in descending order first by the number of past consultations, then by the number of page views. For example, a volunteer with 2 consultations and 20 page views would be listed above another volunteer with 1 consultation and 30 page views. After the change, the results listed all counselors with at least one completed consultation first, in ascending number of completed consultations (and then in descending order of the page views). Those with no consultations were listed last. This change put volunteers with more capacity in more prominent positions and influenced page views. This algorithm change is unlikely to directly affect a volunteer's motivation because volunteers were not aware of the change and did not use the search.

We construct the first instrumental variable as: IVRead $_{i t}$

$=\left\{\begin{array}{cl}0 & \text { if the policy change has occurred by } t \\ \text { ChatCnt }_{i T} & \text { if the policy change has not occurred by } t\end{array}\right.$

where $T$ is the time of policy change. Before the change, the variable takes the value of 0 and after the policy change, it equals the number of consultations the volunteer completed before the change. This reflects how the policy change influences the volunteer's rank in listings. A valid instrument only requires conditional independence with the dependent variable. Since we control for the total number of completed consultations $\left(\right.$ ChatCnt $\left._{i t}\right)$, this instrument $\left(\right.$ IVRead $\left._{i t}\right)$ is unlikely to affect the DV through a higher tendency to accept consultations.

Second, the instrumental variable for appreciation is the log-transformed average word count of the reasons in previous consultation requests before $t$ $\left(\right.$ IVRating $\left.g_{i t}\right)$. Each consultation request includes the reasons for the request, and longer reasons likely indicate more complicated inquiries that may require more communication. It is correlated with a volunteer's current number of ratings because a student is likely more appreciative after a complex question gets answered. On the other hand, the length of reasons received in previous consultation requests should not influence the volunteer's acceptance decision for the current request because the current request has its own features. Therefore, reason length in previous consultation requests is a valid instrument variable for the number of five-star ratings received.

\section{Results}

\subsection{Hypothesis Tests}

We first explore the main effects of the two forms of feedback and report the results from the estimation following three specifications in Table 4. The third model is fully specified with endogeneity control. The first model does not account for endogeneity. The second model does not include the controls.

Table 4: Main Results $(\mathrm{N}=6,414)$

\begin{tabular}{|c|c|c|c|}
\hline DV: Accept & (1) & (2) & (3) \\
\hline N.Readit $_{\text {it }}$ & $\begin{array}{l}-0.0328^{* * \star} \\
(-6.14)\end{array}$ & $\begin{array}{l}-0.116^{\star * \star} \\
(-10.16)\end{array}$ & $\begin{array}{l}-0.0887^{* * *} \\
(-6.56)\end{array}$ \\
\hline N.Rating $i t$ & $\begin{array}{l}0.00658^{* \star *} \\
(3.62)\end{array}$ & $\begin{array}{l}0.0458^{\star \star \star \star} \\
(7.21)\end{array}$ & $\begin{array}{l}0.0254^{+} \\
(1.74)\end{array}$ \\
\hline Recencyit & $\begin{array}{l}-1.25 e-10^{* * *} \\
(-9.62)\end{array}$ & & $\begin{array}{l}-1.42 \mathrm{e}-10^{* \star *} \\
(-10.35)\end{array}$ \\
\hline ScoreDiffit & $\begin{array}{l}-0.0533 \\
(-1.59)\end{array}$ & & $\begin{array}{l}-0.0451 \\
(-1.32)\end{array}$ \\
\hline FirstChati & $\begin{array}{l}0.0231^{\star \star \star *} \\
(3.37)\end{array}$ & & $\begin{array}{l}0.00128 \\
(0.15)\end{array}$ \\
\hline ChatCnt $_{i t}$ & $\begin{array}{l}0.000606 \\
(1.39)\end{array}$ & & $\begin{array}{l}0.000812 \\
(0.53)\end{array}$ \\
\hline T.Schoolit & $\begin{array}{l}0.0136^{\star *} \\
(2.79)\end{array}$ & & $\begin{array}{l}0.0126^{*} \\
(2.53)\end{array}$ \\
\hline T.Major ${ }_{i t}$ & $\begin{array}{l}0.0194^{\star *} \\
(3.22)\end{array}$ & & $\begin{array}{l}0.0177^{\star \star} \\
(2.82)\end{array}$ \\
\hline Hour $_{i t}$ & $\begin{array}{l}-0.000729 \\
(-1.49)\end{array}$ & & $\begin{array}{l}-0.000759 \\
(-1.48)\end{array}$ \\
\hline Fixed Effect & Yes & Yes & Yes \\
\hline Time Effect & Yes & Yes & Yes \\
\hline IVs & No & Yes & Yes \\
\hline
\end{tabular}


\begin{tabular}{lcrr}
$\mathrm{R} 2$ & $28.51 \%$ & $17.46 \%$ & $25.9 \%$ \\
\hline Note: $t$ stat in Paren., ${ }^{+} p<0.1,{ }^{*} p<0.05,{ }^{* * *} p<0.01,{ }^{* * * *} p<0.001$
\end{tabular}

All three models consistently report a positive and

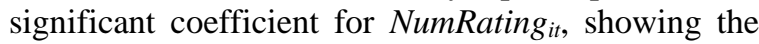
positive marginal effect of appreciation. This finding supports H1. All models report a negative and significant coefficient for NumRead it $_{\text {, indicating that }}$ an increase in attention reduces the likelihood for volunteers to accept additional consultation requests. Therefore, $\mathrm{H} 2$ is not supported.

The first model includes an F-test for the hypothesis that all individual-specific effects are equal to zero. This hypothesis is rejected with an F-statistic of 20.38 (p-value<0.0001). This shows the necessity to control for individual fixed effects, as an OLS model is biased. The second model was presented to show that the model is robust to the potential correlation between independent variables and the control variables. The third model reports both the regression results and a series of statistical tests. The under-identification hypothesis was rejected with pvalue $<0.001$. The weak identification hypothesis was rejected with a Cragg-Donald Wald $\mathrm{F}$ statistics of 41.91. A Hausman test was conducted to compare the estimated coefficients with and without the control of endogeneity, and showed the appropriateness of the specification. These tests show the validity of our instruments in controlling for endogeneity.

\subsection{Moderation Analysis}

We conducted two moderation analyses to explore the underlying mechanism behind the two feedback artifacts. The first moderator we consider is the logtransformed length of the volunteers' answer to the optional question "what other tips do you have for high school graduates?" We denote this variable as LenBio $_{i}$. Compared to other mandatory questions, this optional question sees the largest variation in the length of the response since volunteers are not obligated to answer it. If a volunteer wrote a lengthy answer to this question, it is likely that this volunteer is more generous in helping others and thus more likely to transition to the mode of altruism.

The second moderator is the peer group size, indicated by the number of other volunteers who are from the same college as volunteer $i$ and have received at least one consultation request. We denote this variable as Group . This moderator is associated with the impact of reputation because the presence of other students from the same college will affect the focal volunteer's perceived reputation. With a larger peer group size, the focal volunteer likely perceives himself to obtain a higher reputation gain from positive feedback publicized by the platform [9].

5.2.1. Moderating Effects of Bio Length. From the results reported in Table 5, we observe positive interactions between LenBio $_{i}$ and both independent variables. This shows that generous volunteers are more responsive to feedback in both forms. Notably, the stand-alone effect of NumRating it becomes $^{2}$ insignificant with the inclusion of the interaction term while that of NumReadit remains significant. This indicates that generosity has a greater impact on the mechanism of appreciation than that of attention. Specifically, for volunteers who did not answer this optional question $\left(\right.$ LenBio $\left._{i}=0\right)$, appreciation has no impact on their additional contributions. This is in contrast to attention, whose negative impact is only partially mitigated by volunteers' generosity level. Overall, more generous volunteers seem to be more sensitive to the appreciation cues in terms of the activation into the altruism mode that sustains their continuous participation.

Table 5: Moderation Effect of Bio Length

\begin{tabular}{|c|c|c|}
\hline DV: Accept $(0 / 1)$ & (1) & (2) \\
\hline NumRead $_{i t}$ & $\begin{array}{c}-0.0406^{* * *} \\
(-5.02)\end{array}$ & $\begin{array}{c}-0.159^{* * *} \\
(-6.13)\end{array}$ \\
\hline NumReadit LenBioi & & $\begin{array}{c}0.0181^{* *} \\
(2.98)\end{array}$ \\
\hline NumRating $_{i t}$ & $\begin{array}{c}-0.00681 \\
(-0.29)\end{array}$ & $\begin{array}{c}0.00952^{* * *} \\
(4.92)\end{array}$ \\
\hline NumRating ${ }_{i t} \times$ LenBio $_{i}$ & $\begin{array}{c}0.00885^{*} \\
(2.22)\end{array}$ & \\
\hline Fixed Effect & Yes & Yes \\
\hline Time Effect & Yes & Yes \\
\hline Controls & Yes & Yes \\
\hline IVs & Yes & Yes \\
\hline$N$ & 6,414 & 6,414 \\
\hline
\end{tabular}

5.2.2. Moderating Effects of Peer Group Size. In the second moderation analysis, we observe significant and positive interaction only between attention and peer group size (Table 6). This shows that appreciation is not manifested through observability. We note that a volunteer's rating is neither publicly highlighted in the search result nor used as a search criterion. It is displayed on a volunteer's profile page, but only those who clicked into the detailed page can see it.

The positive interaction between group size and attention shows that larger group size will mitigate the negative impact of attention. This is possibly due to the boosted reputation among closely-knitted groups that makes the volunteer expend effort to meet others' expectations. While $\mathrm{H} 2$ is not supported by the empirical analysis, which we discuss in later sections, 
the argument we used to build $\mathrm{H} 2$ is partially verified in this moderation analysis.

\begin{tabular}{|c|c|c|}
\hline DV: Accept (0/1) & (1) & (2) \\
\hline NumReadit $_{i t}$ & $\begin{array}{c}-0.0440^{* * *} \\
(-5.29)\end{array}$ & $\begin{array}{c}-0.136^{* * *} \\
(-8.67)\end{array}$ \\
\hline NumReadit $\times$ Group $_{i}$ & & $\begin{array}{c}0.00772^{* * *} \\
(4.67)\end{array}$ \\
\hline NumRating & $\begin{array}{c}0.0335^{+} \\
(1.79)\end{array}$ & $\begin{array}{c}0.00947^{\star \star \star} \\
(4.91)\end{array}$ \\
\hline NumRating $_{i t \times}$ Group $_{i}$ & $\begin{array}{c}-0.0000985 \\
(-0.07)\end{array}$ & \\
\hline Fixed Effect & Yes & Yes \\
\hline Time Effect & Yes & Yes \\
\hline Controls & Yes & Yes \\
\hline IVs & Yes & Yes \\
\hline$N$ & 6,414 & 6,414 \\
\hline
\end{tabular}

\subsection{Robustness Checks}

5.3.1. Switching Users. In our main analyses, we included all volunteers who received more than 1 consultation request. However, many volunteers either rejected all requests or accepted all requests. A group of 197 users switched between the two decisions. In this robustness check, we include only volunteers who switched because their behavior provides the strongest identification for us to understand factors that affect a volunteer's decision. The results in Table 7 with and without IVs are consistent with the primary analyses.

\begin{tabular}{|c|c|c|}
\hline DV: Accept $(0 / 1)$ & (1) & (2) \\
\hline NumReadit & $\begin{array}{c}-0.0787^{* * *} \\
(-3.50)\end{array}$ & $\begin{array}{c}-0.0499^{+} \\
(-1.90)\end{array}$ \\
\hline NumRating $_{i t}$ & $\begin{array}{c}0.0227^{+} \\
(1.65)\end{array}$ & $\begin{array}{c}0.0227^{+} \\
(1.72)\end{array}$ \\
\hline Fixed Effect & Yes & Yes \\
\hline Time Effect & Yes & Yes \\
\hline Controls & Yes & Yes \\
\hline IVs & No & Yes \\
\hline$N$ & 1,072 & 1,072 \\
\hline
\end{tabular}

5.3.2. Random Effect Model. We used a fixed-effect model to control for individual heterogeneity in our main analysis, and we also estimate a random effect model in this robustness check. As can be seen from Table 8, our results are consistent as before.

5.3.3. Single Independent Variable. The correlation

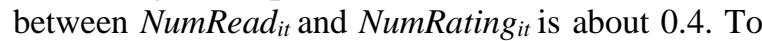
examine the impact of such a correlation, we ran two separate models with each containing only one independent variable. The results in Table 9 are consistent.

Table 8: Robustness - Random Effect

\begin{tabular}{|c|c|c|}
\hline DV: Accept $(0 / 1)$ & (1) & (2) \\
\hline Sample & Switching & All \\
\hline NumRead $_{i t}$ & $\begin{array}{c}-0.0936^{\star * *} \\
(-6.58)\end{array}$ & $\begin{array}{c}-0.0201^{* * *} \\
(-4.00)\end{array}$ \\
\hline NumRating $_{i t}$ & $\begin{array}{c}0.0368^{* * *} \\
(5.45)\end{array}$ & $\begin{array}{c}0.00660^{* * *} \\
(3.64)\end{array}$ \\
\hline Random Effect & Yes & Yes \\
\hline Time Effect & Yes & Yes \\
\hline Controls & Yes & Yes \\
\hline IVs & Yes & Yes \\
\hline$N$ & 1,072 & 6,414 \\
\hline
\end{tabular}

Table 9: Robustness - Single Ind. Variable

\begin{tabular}{lcc}
\hline DV: Accept (0/1) & $(1)$ & $(2)$ \\
\hline NumReadit & $-0.0307^{* * *}$ & \\
& $(-5.77)$ & $0.00503^{* *}$ \\
NumRatingit & & $(2.79)$ \\
& & Yes \\
Fixed Effect & Yes & Yes \\
Time Effect & Yes & Yes \\
Controls & Yes & Yes \\
IVs & Yes & 6414 \\
$N$ & 6414 &
\end{tabular}

\section{Discussion, Limitation, and Conclusion}

This study examined how two commonly used components of online volunteering systems (ratings for users and views of profile pages) influenced the behavior of volunteers. We found that receiving more positive ratings from counselees led counselors to accept more consultations. However, having more page views had the opposite effect.

The number of five-star ratings (appreciation) had a positive effect because a counselee's genuine gratitude and acknowledgment activates a volunteer's altruistic motivation. This is consistent with past studies, and it extends previous works by highlighting the source of appreciation-the individual who directly benefits from the voluntary effort. We believe that the source is critical for the activation of volunteers' altruistic motivation, and this perspective is lacking in the past understanding of feedback. Our measure of appreciation is the number of five-star ratings rather than average ratings as in past research. Our work suggests that future work should explore feedback designs that transmit genuine appreciation from those helped to contributors.

The number of page views (attention) had a negative effect on volunteers' likelihood to accept additional consultations; this finding is different from past research [18]. There are two plausible 
explanations for this. First, it may be that when volunteers see a higher page view count, they feel that they have made sufficient contributions. Mental accounting theory says that people classify personal resources differently [35]. Volunteers may interpret the number of page views as indicating that they have already helped a large number and thus they are less motived to expend additional effect by accepting a consultation request. Alternately, social learning theory argues that people form ideas about whether to continue offering help based on the behavior of the audience. A high page view count indicates that many people have viewed the volunteer's profile page, but decided not to ask for a consultation. Volunteers may take this negatively as they may consider consultation requests to be an approval of their value, and they have been passed over by many students in favor of other volunteers. Future studies can further examine the negative impact of attention and identify potential mechanisms to mitigate this effect.

Taken together, the results present a theoretical conundrum. Attention reduces volunteerism while appreciation increases it. In the psychology literature, feedback has long been considered a highly contextual factor that affects performance in various ways [20, 23]. Our study demonstrates the importance of differentiating feedback cues based on the source, message, and recipient. Most importantly, we evaluate whether an information cue is an accurate reflection of contribution. The theoretical framework of feedback on users' online contribution should incorporate these new perspectives [26].

Such new perspectives generate implications for designers of online volunteering platforms and other similar platforms seeking to maintain an active user base contributing knowledge and effort. Ratings and profile page views are common features of such platforms. Our results show that the page view feature should be considered carefully. Rather than presenting users' cumulative page views, platforms may consider displaying users' recent page views or display the rank of the page view among all volunteers along with the number of page views to avoid the potential negative impact of people misperceiving themselves as having made sufficient contributions.

Our work has its limitations that future studies can extend. First, our study is based on observational data that does not entail controlled manipulation. Future studies can consider running field experiments to understand feedback mechanisms and generate more straightforward conclusions. Second, our data is based on the 2018 event of the college application consultation. This is the first year that the organizers used a centralized online system for this volunteering event. Volunteers' behavior may change if they use this system in subsequent years. However, we believe that this is also an advantage of our data because we suffer less from confounds of time and experience. Last, this college application process and voluntary consulting event are influenced by the specific education policies in China. While the findings may not be directly applicable to other college application contexts, we believe that the insights from this study can be extended to other contexts involving timesensitive online volunteerism. Despite these limitations, we believe that our study provides new perspectives on online contribution and sheds light on practical applications of online volunteerism.

\section{References}

[1] Adamic, L.A., et al. Knowledge sharing and yahoo answers: everyone knows something. in Proceedings of the 17th international conference on World Wide Web. 2008. ACM.

[2] Amichai-Hamburger, Y., Potential and promise of online volunteering. Computers in Human Behavior, 2008. 24(2): p. 544-562.

[3] Andreoni, J., Impure altruism and donations to public goods: A theory of warm-glow giving. The economic journal, 1990. 100(401): p. 464-477.

[4] Bandura, A. and R.H. Walters, Social learning theory. Vol. 1. 1977: Prentice-hall Englewood Cliffs, NJ.

[5] Batson, C.D., et al., Is empathic emotion a source of altruistic motivation? Journal of Personality and Social Psychology, 1981. 40(2): p. 290.

[6] Bénabou, R. and J. Tirole, Incentives and prosocial behavior. American economic review, 2006. 96(5): p. 16521678.

[7] Chen, J., Y. Ren, and J. Riedl. The effects of diversity on group productivity and member withdrawal in online volunteer groups. in Proceedings of the SIGCHI conference on human factors in computing systems. 2010. ACM.

[8] Cnaan, R.A. and R.S. Goldberg-Glen, Measuring motivation to volunteer in human services. The journal of applied behavioral science, 1991. 27(3): p. 269-284.

[9] Coleman, J.S., Social capital in the creation of human capital. American journal of sociology, 1988. 94: p. S95S120.

[10] Crocker, J., A. Canevello, and A.A. Brown, Social motivation: Costs and benefits of selfishness and otherishness. Annual Review of Psychology, 2017. 68: p. 299-325. 
[11] Dellarocas, C. and R. Narayan. What motivates consumers to review a product online? A study of the product-specific antecedents of online movie reviews. in WISE. 2006.

[12] Duan, W., B. Gu, and A.B. Whinston, Do online reviews matter? - An empirical investigation of panel data. Decision support systems, 2008. 45(4): p. 1007-1016.

[13] Dubé, J.-P., X. Luo, and Z. Fang, Self-signaling and prosocial behavior: A cause marketing experiment. Marketing Science, 2017. 36(2): p. 161-186.

[14] Fernandes, M.F. and D.M. Randall, The nature of social desirability response effects in ethics research. Business Ethics Quarterly, 1992: p. 183-205.

[15] Frisch, M.B. and M. Gerrard, Natural helping systems: A survey of Red Cross volunteers. American Journal of Community Psychology, 1981. 9(5): p. 567-579.

[16] Harrison, D.A., Volunteer motivation and attendance decisions: Competitive theory testing in multiple samples from a homeless shelter. Journal of applied psychology, 1995. 80(3): p. 371.

[17] Hsieh, G., et al. Welcome!! social and psychological predictors of volunteer socializers in online communities. in Proceedings of the 2013 conference on Computer supported cooperative work. 2013. ACM.

[18] Huang, N., et al., Motivating user-generated content with performance feedback: Evidence from randomized field experiments. Management Science, 2018. 65(1): p. 327-345.

[19] Ilgen, D.R., C.D. Fisher, and M.S. Taylor, Consequences of individual feedback on behavior in organizations. Journal of applied psychology, 1979. 64(4): p. 349.

[20] Jabr, W., et al., Leveraging philanthropic behavior for customer support: the case of user support forums. MIS Quarterly, Forthcoming, 2013.

[21] Jones, C. Microvolunteering: what is it and why should you do it? 2017 [cited 2019 6/4]; Available from: https://www.theguardian.com/voluntary-sectornetwork/2017/apr/13/microvolunteering-what-is-it-andwhy-should-you-do-it.

[22] Kanefsky, B., N.G. Barlow, and V.C. Gulick, Can distributed volunteers accomplish massive data analysis tasks. Lunar and Planetary Science, 2001. 1: p. 32.

[23] Kluger, A.N. and A. DeNisi, The effects of feedback interventions on performance: A historical review, a metaanalysis, and a preliminary feedback intervention theory. Psychological bulletin, 1996. 119(2): p. 254.
[24] Lafky, J., Why do people rate? Theory and evidence on online ratings. Games and Economic Behavior, 2014. 87: p. 554-570.

[25] Lunden, I. LinkedIn rolls out its Career Advice mentoring program to US, UK and India. 2017 [cited 2019 8/26/2019]; Available from: https://techcrunch.com/2017/11/15/linkedin-rolls-out-itscareer-advice-mentoring-program-to-us-uk-and-india/.

[26] Ma, M. and R. Agarwal, Through a glass darkly: Information technology design, identity verification, and knowledge contribution in online communities. Information systems research, 2007. 18(1): p. 42-67.

[27] Miller, H. and R. Mather. The presentation of self in WWW home pages. in IRISS 98 Conference, Bristol. 1998.

[28] Mischel, W., E.B. Ebbesen, and A.R. Zeiss, Selective attention to the self: Situational and dispositional determinants. Journal of Personality and Social Psychology, 1973. 27(1): p. 129

[29] Moon, J.Y. and L.S. Sproull, The role of feedback in managing the Internet-based volunteer work force. Information Systems Research, 2008. 19(4): p. 494-515.

[30] Morrow-Howell, N. and A.C. Mui, Elderly volunteers: Reasons for initiating and terminating service. Journal of Gerontological Social Work, 1989. 13(3-4): p. 21-34.

[31] Qiu, L. and S. Kumar, Understanding voluntary knowledge provision and content contribution through a social-media-based prediction market: A field experiment. Information Systems Research, 2017. 28(3): p. 529-546.

[32] Ross, M. and G.J. Fletcher, Attribution and social perception. The handbook of social psychology, 1985. 2: p. 73-114.

[33] Rotman, D., et al. Dynamic changes in motivation in collaborative citizen-science projects. in Proceedings of the ACM 2012 conference on computer supported cooperative work. 2012. ACM.

[34] Swann Jr, W.B. and M. Brooks, Why threats trigger compensatory reactions: The need for coherence and quest for self-verification. Social Cognition, 2012. 30(6): p. 758777.

[35] Thaler, R., Mental accounting and consumer choice. Marketing science, 1985. 4(3): p. 199-214.

[36] UN Volunteers, 2015 State of the World's Volunteerism Report. 2015.

[37] Wolford, M., K. Cox, and K. Culp, Effective motivators for master volunteer program development. Journal of extension, 2001. 39(2): p. 1-8. 